\title{
New data on aetiology of nodular gill disease in rainbow trout, Oncorhynchus mykiss
}

\author{
Iva Dyková ${ }^{1}$, Martin Kostka ${ }^{1,2}$, Falk Wortberg $^{3}$, Elisabeth Nardy $^{3}$ and Hana Pecková ${ }^{1}$ \\ ${ }^{1}$ Institute of Parasitology, Biology Centre of the Academy of Sciences of the Czech Republic, Branišovská 31, 37005 České \\ Budějovice, Czech Republic; \\ ${ }^{2}$ Faculty of Agriculture, University of South Bohemia, České Budějovice, Czech Republic; \\ ${ }^{3}$ Chemisches und Veterinäruntersuchungsamt Stuttgart, Schaflandstr. 3/3, 70736 Fellbach, Deutschland
}

\begin{abstract}
We studied amoebae associated with nodular gill disease (NGD) outbreaks in rainbow trout Oncorhynchus mykiss (Walbaum) in fish farms in South-Western Germany. Gills of 12 diseased rainbow trout were examined in fresh, by isolation attempts, histologically and using in situ hybridisation (ISH). A total of nine amoeba strains of the genera Acanthamoeba (1), Hartmannella (2), Naegleria (1), Protacanthamoeba (1) and Vannella (4) were isolated and determined using light microscopical, ultrastructural and molecular methods. Specific molecular probes designed from the SSU rDNA sequences of individual amoeba strains were used for non-radioactive ISH in histological sections. Association of Naegleria sp. with NGD and a direct ISH proof of Naegleria trophozoites attached to hyperplastic gill epithelium are novel findings, expanding the number of possible agents of NGD and supporting the hypothesis on multicausal aetiology of this disease.
\end{abstract}

Keywords: nodular gill disease, aetiological study, amoebae, Naegleria sp., fish diseases, aquaculture, Oncorhynchus mykiss

As against Amoebic Gill Disease (AGD) of marine fish, the association of amoebae with gill disease of freshwater fish has received less attention. Daoust and Ferguson (1985) were the first to describe Nodular Gill Disease (NGD) in salmonids as multi-focal epithelial hyperplasia characterized by the presence of amoebae (family Cochliopodidae). Later, Cochliopodium sp. (Ferguson 2006) and Thecamoeba hoffmani Sawyer, Hnath et Conrad, 1974 (Sawyer et al. 1974, 1975) were reported as the agents of gill disease in salmonids. Unfortunately, none of these nor several other reports of gill disease attributed to amoebae in freshwater salmonids (Buchmann et al. 2004, Antychowicz 2007, Tubbs et al. 2010) included a detailed diagnosis or an adequate documentation of the agent.

We have no doubts that amoebae can play an important role in gill disease outbreaks. However, the participation of amoebae in many of these outbreaks may pass unreported due to the difficulty in recognition of amoebae in both fresh preparations and routinely stained histological sections, in which amoeba species/generic determination is practically impossible. Recently, progress in molecular characterisation of freshwater and marine free-living amoebae including those infecting fish (Dyková and Lom 2004, Dyková et al. 2005a,b,c,d, 2006, 2008a,b,c,d,e, Smirnov et al. 2005, 2007, 2008, Young et al. 2007, 2008a,b, Tekle et al. 2008) has facilitated specific ap- proaches to studies of the aetiology of amoebic diseases of fish.

Over a past few years, an increasing number of NGD outbreaks have been detected in rainbow-trout farms in the South West of Germany. In 2008, two of the current authors (E.N. and F.W.) diagnosed outbreaks of NGD that caused severe economical losses in five salmonid farms. The current authors confirmed the original clinical diagnosis of NGD by detection of amoebae in fresh gill tissue in the field, later in histological sections, continued the study also by other methods, and present the results herein.

\section{MATERIALS AND METHODS}

In May of 2009, twelve rainbow trout Oncorhynchus mykiss (Walbaum) of marketing size were sampled in five farms (denominated here as B, E, F, K and L) where repeated outbreaks of gill disease manifested by severe clinical symptoms of NGD had occurred over a few past years. Small pieces of gill tissue were examined in fresh and several samples of fresh gill tissue from each fish were taken for isolation of amoebae, using non-nutrient amoeba saline agar in Petri dishes (Page 1988, Kalinina and Page 1992). Several complete gill arches of each fish were fixed and routinely processed for histology. Aetiological diagnosis of this disease condition was based on the isolation of amoebae from the affected gill tissue followed by histological examination and in situ hybridisation (ISH). 
Clonal cultures derived from primary isolates of amoebae were studied by light and electron microscopy and using molecular methods as described elsewhere (Dyková et al. 2005a,b,c,d, 2006, 2008a,b,c,d). SSU rDNA sequences generated for isolated amoeba strains were used as markers that confirmed morphological determination and served as a basis for design of molecular probes. Oligonucleotide probes were designed where suitable mis-matches were observed in aligned sequences so as to be specific to the isolated strains of amoebae. These probes were used for non-radioactive ISH in selected histological sections (i.e., sections obtained in series with the sections proven amoebae-positive by routine staining with haematoxylin-eosin; $\mathrm{HE})$. The protocols for hybridisation based on fluorescein-labelled probe and Anti-Fluo-AP/NBT/BCIP system (www.rocheapplied-science.com) were adopted from Young et al. (2007). The probes were synthesized by Metabion (East Port, Praha) and checked up using ISH procedure with trophozoites of corresponding strains that were either attached to poly-lysine coated slides or fixed on agar plates and then pelleted, embedded in Histoplast and sectioned as if they were tissue material.

Gill tissue sections from rainbow trout were also hybridized on poly-lysine coated slides. In view that a Cochliopodium sp. has been reported as the agent of NGD (Ferguson 2006), the series of hybridized controls included a strain of Cochliopodium from our collection. In situ hybridisations were performed with gill tissue sections containing a reasonable number of attached amoebae.

\section{RESULTS}

\section{Gill lesions}

The grossly visible lesions on rainbow trout gills that determined the material sampled from the 12 fish consisted of a diffuse swelling, excess of mucus and pronounced colour changes manifested as pale nodules (Fig. 1). Histologically, massive epithelial proliferation, loss of gill architecture and desquamation of the gill epithelium were observed. Marked epithelial hyperplasia resulted in enlargement of terminal parts of gill filaments and extensive lamellar fusion with obliteration of interlamellar spaces. These lesions corresponded to the gross signs of gill disease and were observed in histological sections from all fish examined, irrespective of the number of amoebae preserved in the altered parts of gills. Trophozoites of amoebae were found either in small groups or in continuous layers on the surface of gill epithelium (Figs. 2-5). Samples of well-fixed material revealed a relatively firm attachment of amoebae to the surface of hyperplastic epithelium. In some cases, extensive hyperplasia of the epithelium contributed to the impression of a deep penetration of trophozoites into the epithelium. The observed lesions fully corresponded to those earlier described in NGD (Ferguson 2006). Concerning the presence of amoebae in histological sections, gills of individual rainbow trout differed substantially. Large numbers of amoebae attached to the surface of hyperplastic epithelium were found in gills of 2 of 12 examined rainbow trout (from

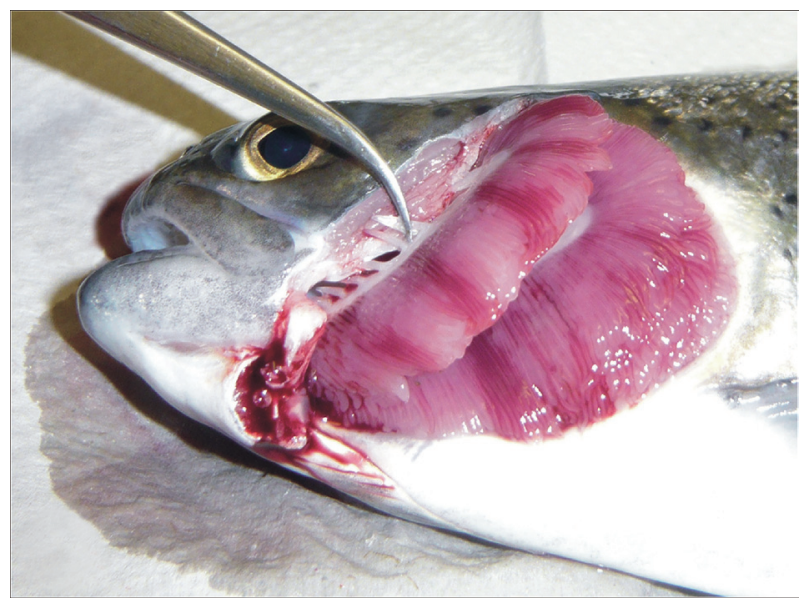

Fig. 1. Advanced stage of nodular gill disease grossly manifested in rainbow trout Oncorhynchus mykiss as swelling of gills with multiple pale nodules. Natural size.

Table 1. Amoeba strains isolated from rainbow trout Oncorhynchus mykiss gills with signs of nodular gill disease.

\begin{tabular}{llll}
\hline $\begin{array}{l}\text { Strain } \\
\text { denomination }\end{array}$ & $\begin{array}{l}\text { Local } \\
\text { origin }\end{array}$ & Generic assignment & $\begin{array}{l}\text { SSU rDNA Gen- } \\
\text { Bank Acc. No. }\end{array}$ \\
\hline GERB & Farm B & Vannella sp. & HM363624 \\
GERE3 & Farm E & Protacanthamoeba sp. & HM363625 \\
GERF1 & Farm F & Hartmannella sp. & HM363625 \\
GERF2 & Farm F & Hartmannella sp. & HM363625 \\
GERF3 & Farm F & Acanthamoeba sp. & HM363628 \\
GERK & Farm K & Naegleria sp. & HM363628 \\
GERL14 & Farm L & Vannella sp. & HM363628 \\
GERL34 & Farm L & Vannella sp. & HM363628 \\
GERL41 & Farm L & Vannella sp. & HM363632 \\
\hline
\end{tabular}

farms $\mathrm{K}$ and $\mathrm{E}$ ) whereas individual amoebae or small groups of trophozoites were found in gill sections from the other 10 specimens. Enormous extent of hyperplastic lesions and pronounced desquamation of the epithelium suggested that most fish were sampled in the late stage of amoebic infection. As expected from our previous experience, no features characterizing individual genera of amoebae could be distinguished in histological sections. In some specimens, the presence of filamentous bacteria apposed to lamellar epithelium was observed.

\section{Amoebae isolated from NGD-affected gills}

Thirteen primary isolates of amoebae were obtained from gill samples of 12 rainbow trout showing signs of NGD. Repeated subculturing of these isolates enabled establishment of refined cultures of nine strains whereas four primary isolates (that consisted of minute amoebae) were lost due to bacterial overgrowth. Based on their morphology and molecular analysis, four strains (GERB, GERL14, GERL34, GERL41) were assigned to Vannella Bovee, 1965 (Figs. 12, 13), two (GERF1, GERF2) to Hartmannella Alexeieff, 1912 (Fig. 12), one (GERK) to Naegleria Alexeieff, 1912 (Fig. 12), one (GERE3) to 


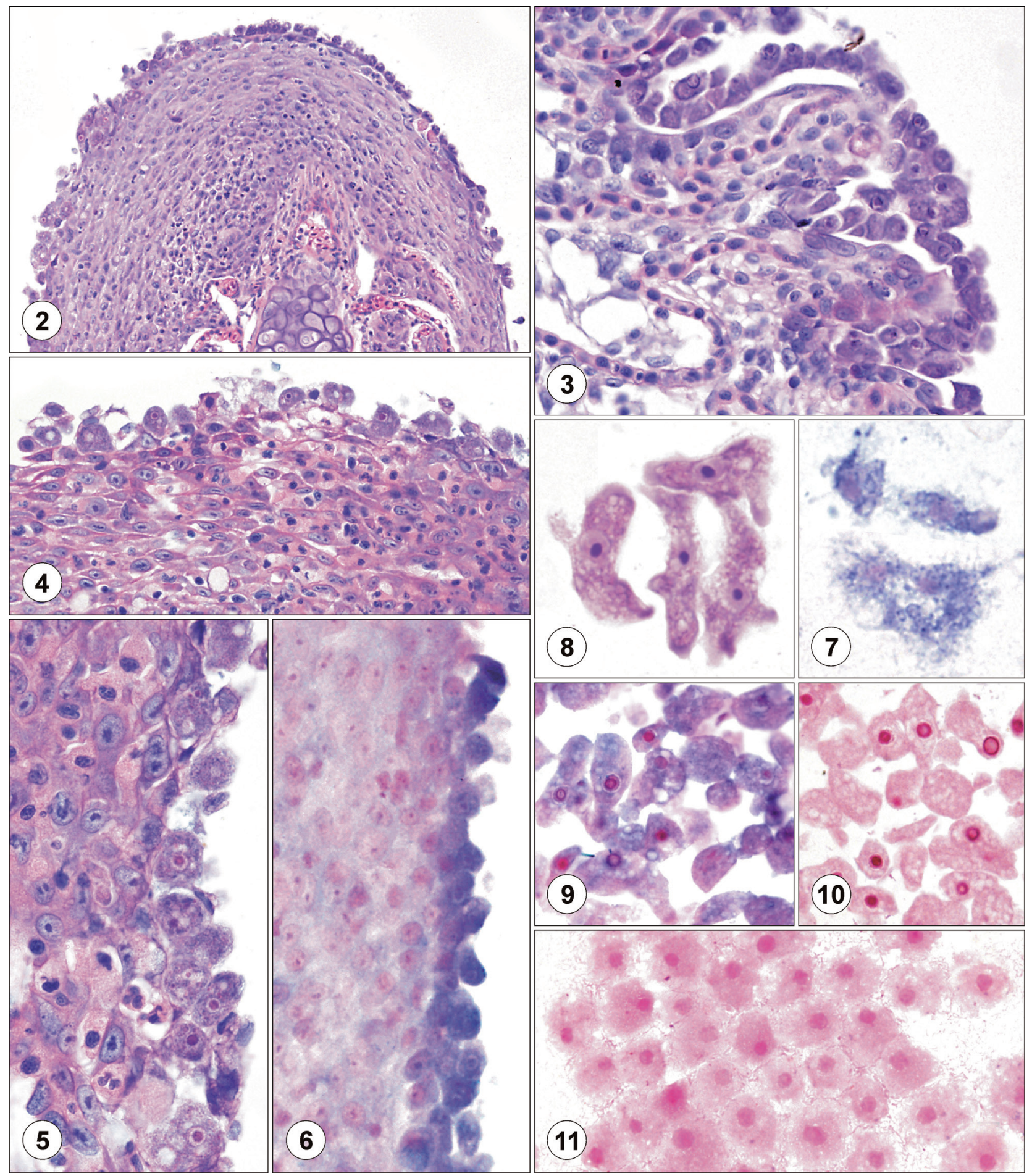

Figs. 2-5. Histopathology of nodular gill disease of rainbow trout Oncorhynchus mykiss. Fig. 2. An apical part of gill filament with pronounced hyperplasia of epithelium and a continuous layer of attached amoeba trophozoites on its surface. Fish from farm K. HE, $\times 150$. Fig. 3. Fusion of gill secondary lamellae due to hyperplasia of epithelium and amoeba trophozoites attached to the surface of lateral part of gill filament. Fish from farm K. HE, $\times 325$. Figs. 4, 5. Surface of hyperplastic gill epithelium with attached amoeba trophozoites. Fish from farm E. HE, $\times 270$ and $\times 480$, respectively. Figs. 6-11. In situ hybridisation (ISH) with oligonucleotide probes complementary to amoeba rRNA sequences. Fig. 6. Amoeba trophozoites identified with the isolated Naegleria strain; ISH in histological section, $\times 480$. Figs. 7. Positive control; cultured Naegleria trophozoites hybridized on poly-lysine coated slide (trophozoites were isolated from the gills of the same fish as in Fig. 6), $\times 720$. Fig. 8. Naegleria trophozoites attached to slide and stained with HE for comparison (same culture as in Fig. 6), ×720. Fig. 9. Positive ISH of pelleted Naegleria trophozoites embedded in Histoplast, $\times 700$. Fig. 10. Negative ISH of pelleted Naegleria trophozoites (Cochliopodium probe), $\times 700$. Fig. 11. Negative ISH of cultured Cochliopodium trophozoites (Naegleria probe), $\times 720$. 


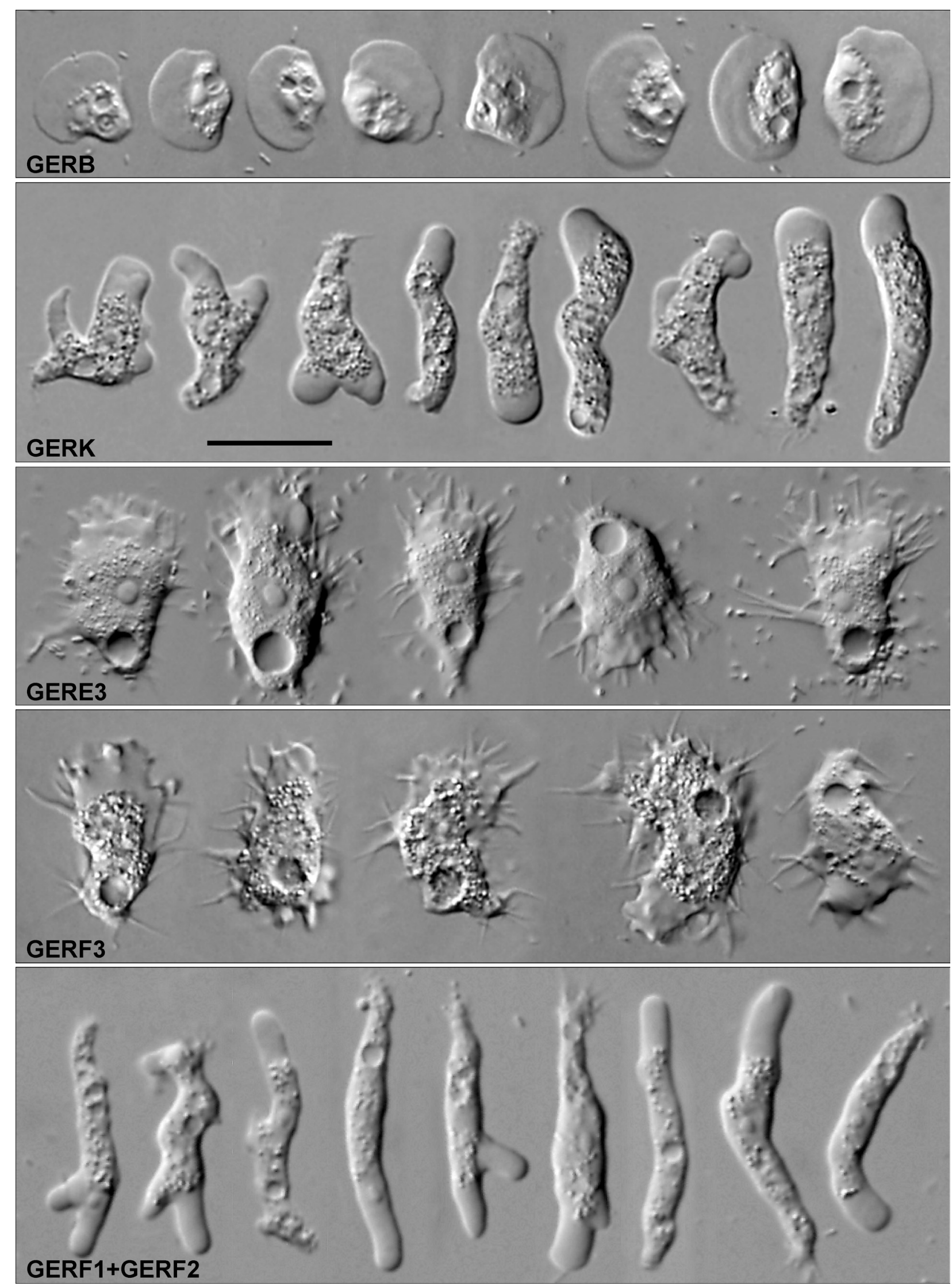

Fig. 12. Trophozoites of amoeba strains isolated from gills of rainbow trout Oncorhynchus mykiss under study, as seen in light microscope equipped with Nomarski optics: Vannella sp. (GERB); Naegleria sp. (GERK); Protacanthamoeba sp. (GERE3); Acanthamoeba (GERF3); Hartmannella sp. (GERF1 + GERF2). Scale bar $=20 \mu \mathrm{m}$. 

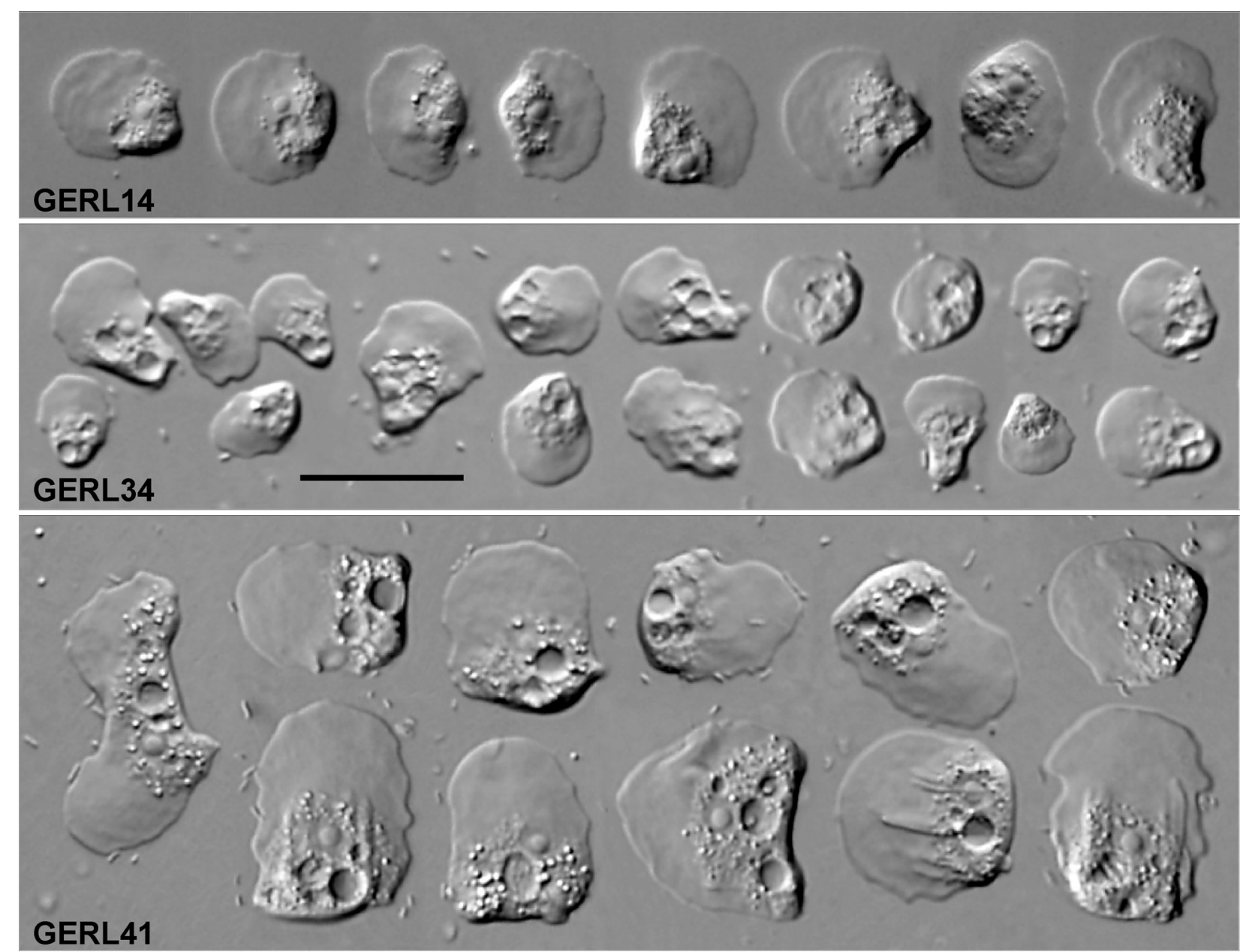

Fig. 13. Trophozoites of amoeba strains isolated from gills of rainbow trout Oncorhynchus mykiss under study, as seen in light microscope equipped with Nomarski optics: Vannella spp. (GERL14, GERL34, GERL41). Scale bar $=20 \mu \mathrm{m}$.

Protacanthamoeba Page, 1981 (Fig. 12) and one (GERF3) to Acanthamoeba Volkonsky, 1931 (Fig. 12). The local origin of strains, the generic assignment, and Acc. Nos. of SSU rDNA sequences deposited in GenBank are summarized in Table 1. The Naegleria strain (GERK) isolated from rainbow trout sampled in farm $\mathrm{K}$ (from a fish with histologically proven infection with amoeba trophozoites) was found to be closely related to Naegleria strains isolated previously from gills of roach Rutilus rutilus (L.) and skin of wels catfish Silurus glanis L. (Dyková et al. 2006).

The generic diagnosis of the isolated amoeba strains revealed a broad spectrum of possible agents of gill lesions, but did not allow relating them to amoebae found in histological material.

\section{In situ hybridisation (ISH)}

Two fluorescein-labelled oligonucleotide probes were designed to target SSU rRNA of Naegleria strain GERK. Their sequences were TCT CCA CAC CTT TAG GTG GG (probe Naeg1) and CGG TCA GGG CCT TAC GGT
T (probe Naeg2). Another two probes targeted SSU rRNA of Cochliopodium: GTG AAC AGC TTA TTA TAA AAG $\mathrm{T}$ (Coch1) and CAT TGA ATA ATA GAG TAT GGG (Coch2).

Within the set of 12 rainbow trout, the final step of aetiological diagnostic procedure was successfully completed for one fish from farm K. Supported with a series of controls that included also Cochliopodium sp., the ISH proved that amoebae in affected gills of rainbow trout were identical with naegleriae obtained by isolation, i.e. GERK strain of Naegleria sp.; at the same time, Cochliopodium sp. was excluded as agent of NGD in the case under study (Figs. 6-11).

\section{DISCUSSION}

The direct diagnosis of Naegleria sp. in rainbow trout gill lesions that were identical with those described in NGD originally (Daoust and Ferguson 1985, Ferguson 2006) extends our knowledge on aetiology of this gill disease. Our finding is entirely consistent with the concept 
of free-living amoebae as potential pathogens and emphasizes that the role of amoebae in gill disease conditions of freshwater fish should be further studied.

In the current study, rainbow trout gills with gross signs of NGD contained sufficient number of amoebae for isolation attempts; unfortunately, histological sections mostly contained only a low number of trophozoites available for ISH. This is why the role in aetiology of gill lesions could not be clarified for all isolated species of amoebae. The low number of amoebae attached to the gill epithelium at the moment of sampling was probably related to the late stage of gill disease condition with disturbances of microcirculation, excessive mucus production and desquamation of epithelium. A low attachment ability of old amoeba trophozoites, histological treatment and the many steps included in the ISH procedure most probably also contributed to the loss of target cells. It is therefore concluded that the adequate selection of histological sections is a crucial step in similar aetiological studies. Of the same importance is the preparation of reference material for testing oligonucleotide hybridisation probes, i.e. pelleted cells of defined cultures of amoebae.

Although the nature of histological sections available for ISH did not allow us to test the role of some amoeba species isolated from the gills, i.e., Acanthamoeba sp., Hartmannella sp. and Protacanthamoeba sp., we do consider those as potential agents of NGD. In contrast, vannellids, which prevailed among the isolated strains, are known as the most frequent and most easily culturable amoebae present on gills of "healthy fish". In consequence, their presence in NGD cases is considered rather accidental.

Due to the fact that we did not follow the genesis of gill lesions from the very beginning, a non-amoeboid (e.g. bacterial) cause of hyperplastic lesions in early stages of disease cannot be excluded. Then the role of free-living amoebae could be poorly opportunistic. This model of NGD ("amoebic gill infestation") as a secondary complication of bacterial gill disease in Arctic char (Salvelinus alpinus) has been described in a careful study by Speare (1999).

Acknowledgements. Financial support was provided by the Grant Agency of the Czech Republic (524/09/0137), the Ministry of Education, Youth and Sports of the Czech Republic (MSM 6007665801) and by research projects of the Institute of Parasitology, Biology Centre of the Academy of Sciences of the Czech Republic (Z60220518 and LC522).

\section{REFERENCES}

Antychowicz J. 2007: Study on rainbow trout nodular gill disease detected in Poland. Bull. Vet Inst. Pulawy 51: 547-551.

Buchmann K., Nielsen T., Sigh J., Bresciani J. 2004: Amoebic gill infections of rainbow trout in freshwater ponds. Bull. Eur. Assoc. Fish Pathol. 24: 87-91.

Daoust P.-Y., Ferguson H.W. 1985: Nodular gill disease: a unique form of proliferative gill disease in rainbow trout, Salmo gairdneri Richardson. J. Fish Dis. 8: 511-522.

Dyková I., Boháčová L., Fiala I., Macháč́oová B., Pecková H., Dvoř́xovÁ H. 2005a: Fish-isolated amoebae of the genera Vannella Bovee, 1965 and Platyamoeba Page, 1969 and their phylogeny inferred from SSU rRNA gene and ITS sequences. Eur. J. Protistol. 41: 219-230.

Dyková I., Fiala I., Dvořáková H., Pecková H. 2008a: Living together: The marine amoeba Thecamoeba hilla Schaeffer, 1926 and its endosymbiont Labyrinthula sp. Eur. J. Protistol. 44: $308-316$

Dyková I., Fiala I., Pecková H. 2008b: Neoparamoeba spp. and their eukaryotic endosymbionts similar to Perkinsela amoebae (Hollande, 1980): Coevolution demonstrated by SSU rRNA gene phylogenies. Eur. J. Protistol. 44: 269-277.

Dyková I., Fiala I., Pecková H., Dvořáková H. 2008c: Phylogeny of Flabellulidae (Amoebozoa: Leptomyxida) inferred from SSU rDNA sequences of the type strain of Flabellula citata Schaeffer, 1926 and newly isolated strains of marine amoebae. Folia Parasitol. 55: 256-264.

Dyková I., Kostka M., Pecková H.: 2008d: Morphology and SSU rDNA-based phylogeny of a new strain of Saccamoeba sp. (Saccamoeba Frenzel, 1892, Amoebozoa). Acta Protozool. 47: $397-405$

Dyкоví I., Lom J. 2004: Advances in the knowledge of amphizoic amoebae infecting fish. Folia Parasitol. 51: 81-97.
Dyková I., Nowak B., Crosbie P.B.B., Fiala I., Pecková H., Adams M.B., Macháč́ová B., Dvořáková H. 2005b: Neoparamoeba branchiphila $\mathrm{sp} . \mathrm{n}$., and related species of the genus Neoparamoeba Page, 1987: morphological and molecular characterisation of selected strains. J. Fish. Dis. 28: 49-64.

Dyková I., Pecková H., Fiala I., Dvořáková H. 2006: Fish-isolated Naegleria strains and their phylogeny inferred from ITS and SSU rDNA sequences. Folia Parasitol. 53: 172-180.

Dyková I., Pecková H., Kostka M. 2008e: Introduction of Mayorella gemmifera Schaeffer, 1926 into phylogenetic studies of Amoebozoa. Acta Protozool. 47: 205-210.

Dyková I., Pindová Z., Fiala I., Dvořáková H., Macháč́ová B. 2005c: Fish-isolated strains of Hartmannella vermiformis Page, 1967: morphology, phylogeny and molecular diagnosis in tissue lesions. Folia Parasitol. 52: 295-333.

Dyková I., Veverková-Fialová M., Fiala I., Dvořáková H. 2005d: Protacanthamoeba bohemica n. sp., isolated from the liver of tench, Tinca tinca (Linnaeus, 1758). Acta Protozool. 44: 369-376.

Ferguson H.W. 2006: Systemic Pathology of Fish: A Text and Atlas of Normal Tissues in Teleosts and their Responses in Disease. 2nd ed. Scotian Press, London, UK, 368 pp.

Kalinina L.V., PAGE F.C. 1992: Culture and preservation of naked amoebae. Acta Protozool. 31: 115-126.

Page F.C. 1988: A New Key to Freshwater and Soil Gymnamoebae. Freshwater Biological Association, Ambleside, Cumbria, $122 \mathrm{pp}$.

Sawyer T.K., Hnath J.G., Conrad J.F. 1974: Thecamoeba hoffmani sp. n. (Amoebida: Thecamoebidae) from gills of fingerling salmonid fish. J. Parasitol. 60: 677-682.

Sawyer T.K., Hoffman G.L., Hnath J.G., Conrad J.F. 1975: Infection of salmonid fish gills by aquatic amoebas (Amoebida: 
Thecamoebidae). In: W.E. Ribelin and G. Migaki (Eds.), The Pathology of Fishes. University of Wisconsin Press, Madison, Wisconsin, pp. 143-150.

Smirnov A., Nassonova E., Berney C., Fahrni J., Bolivar I., Pawlowski J. 2005: Molecular phylogeny and classification of the lobose amoebae. Protist 156: 129-142.

Smirnov A.V., Nassonova E.S., Chao E., Cavalier-Smith T. 2007: Phylogeny, evolution and taxonomy of vannellid amoebae. Protist 158: 295-324.

Smirnov A.V., Nassonova E.S., Cavalier-Smith T. 2008: Correct identification of species makes the amoebozoan rRNA tree congruent with morphology for the order Leptomyxida Page, 1987; with description of Acramoeba dendricola n. g., n. sp., originally misidentified as "Gephyramoeba sp.". Eur. J. Protistol. 44: 35-44.

Speare D.J. 1999: Nodular gill disease (amoebic gill infestation) in char, Salvelinus alpinus. J. Comp. Pathol. 121: 277-282.

Tekle Y.I., Grant J., Anderson O.R., Nerad T.A., Cole J.C., Patterson D.J., Katz L.A. 2008: Phylogenetic placement of diverse amoebae inferred from multigene analyses and assessment of clade stability within 'Amoebozoa' upon removal of varying rate classes of SSU-rDNA. Mol. Phylogenet. Evol. 47: 339-52.

Tubbs L., Wybourne B.A., Lumsden J.S. 2010: Nodular gill disease causing proliferative branchitis and mortality in Chinook salmon (Oncorhynchus tshawytscha). N. Z. Vet. J. 58: 59-61.

Young N.D., Crosbie P.B.B., Adams M.B., Nowak B.F., MorRISON R.N. 2007: Neoparamoeba perurans n. sp., an agent of amoebic gill disease of Atlantic salmon (Salmo salar). Int. J. Parasitol. 37: 1469-1481.

Young N.D., Dyková I., Nowak B., Morrison R.N. 2008a: Development of a diagnostic PCR to detect Neoparamoeba perurans, agent of amoebic gill disease. J. Fish Dis. 31: 285-295.

Young N.D., Dyková I., Snekvik K., Nowak B.F., Morrison R.N. 2008b: Neoparamoeba perurans is a cosmopolitan aetiological agent of amoebic gill disease. Dis. Aquat. Org. 78: 217-223.

Accepted 8 July 2010 